\title{
REVIEW
}

Open Access

\section{Barriers and facilitators to implementation of menu labelling interventions from a food service industry perspective: a mixed methods systematic review}

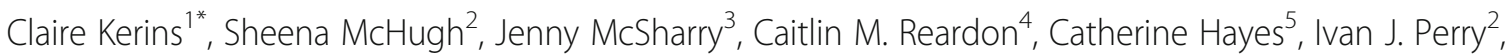
Fiona Geaney ${ }^{2}$, Suzanne Seery ${ }^{6}$ and Colette Kelly ${ }^{1}$

\begin{abstract}
Background: Eating outside the home contributes to poor dietary habits worldwide and is associated with increased body fat and weight gain. Evidence shows menu labelling is effective in promoting healthier food choices; however, implementation issues have arisen. The purpose of this systematic review was to synthesise the evidence on the perceived barriers and facilitators to implementation of menu labelling interventions from the perspective of the food service industry.

Methods: Peer-reviewed and grey literature were searched using databases, specialised search engines and public health organisation websites. Screening reference lists, citation chaining and contacting authors of all included studies were undertaken. Primary research studies relevant to direct supply-side stakeholders were eligible for inclusion. There were no restrictions on menu labelling scheme or format, study methods, publication year or language. At least two independent reviewers performed study selection, data extraction and quality appraisal. The results were synthesised using the 'best fit' framework synthesis approach, with reference to the Consolidated Framework for Implementation Research (CFIR).

Results: Seventeen studies met the eligibility criteria, with the majority rated as average quality $(n=10)$. The most frequently cited barriers were coded to the CFIR constructs 'Consumer Needs \& Resources' (e.g. lack of customer demand for/interest in menu labelling, risk of overwhelmed/confused customers) and 'Compatibility' with organisation work processes (e.g. lack of standardised recipes, limited space on menus). Frequently cited facilitators were coded to the CFIR constructs 'Relative Advantage' of menu labelling (e.g. improved business image/ reputation) and 'Consumer Needs \& Resources' (e.g. customer demand for/interest in menu labelling, providing nutrition information to customers). An adapted framework consisting of a priori and new constructs was developed, which illustrates the relationships between domains.

(Continued on next page)
\end{abstract}

\footnotetext{
* Correspondence: c.kerins2@nuigalway.ie

'Discipline of Health Promotion, School of Health Sciences, National University of Ireland Galway, University Road, Galway, Ireland

Full list of author information is available at the end of the article
} 


\begin{abstract}
(Continued from previous page)
Conclusion: This review generates an adapted CFIR framework for understanding implementation of menu labelling interventions. It highlights that implementation is influenced by multiple interdependent factors, particularly related to the external and internal context of food businesses, and features of the menu labelling intervention. The findings can be used by researchers and practitioners to develop or select strategies to address barriers that impede implementation and to leverage facilitators that assist with implementation effort.
\end{abstract}

Trial registration: Systematic review registration: PROSPERO CRD42017083306.

Keywords: Menu labelling, Implementation, Barriers, Facilitators, Mixed methods, Systematic review, Consolidated framework for implementation research, Best fit framework synthesis

\section{Background}

Poor diet is a leading risk factor for chronic disease and premature death $[1,2]$. Over the past decade, eating outside the home has been highlighted as one of the many factors contributing to poor dietary habits worldwide. Studies have shown that eating outside the home is associated with higher energy and fat intake, lower micronutrient intake [3-7], increased body fat and weight gain [8-11]. The average energy content of main meals served in both fast food and full service restaurants exceed public health recommendations (i.e. $600 \mathrm{kcal}$ or less for main lunch/dinner meals) [12, 13]. In addition, consumers tend to underestimate the energy, fat and sodium content of meals when eating outside the home $[14,15]$. Over the last decades eating outside the home has steadily increased, with fewer meals being prepared at home $[5,16,17]$.

The food service industry, with responsibility for meals prepared outside the home, has an important role in promoting healthy dietary behaviours [18]. To help increase transparency in the nutritional value of meals outside the home and to assist consumers in making both informed and healthier food choices, menu labelling is recommended as part of a comprehensive approach to reduce diet-related non-communicable diseases (NCDs) [19, 20]. Menu labelling includes the provision of nutrition information on menus at the point of sale. Evidence from a recent Cochrane review suggests calorie menu labelling may reduce energy purchased per meal by an average of $8 \%$ [21]. Moreover, a recent systematic review and meta-analysis suggests menu labelling effects consumer dietary intake (i.e. $7 \%$ reduction in energy, $11 \%$ reduction in total fat and $14 \%$ increase in vegetable intake) and industry practices (i.e. reformulation of menu items to lower sodium intake by $9 \%$ ) [22]. The review found no difference in effect by label type (numeric - using numerical information or interpretive - using graphics, symbols or colours) [22].

In an effort to stem the rise in obesity and other dietrelated NCDs, several countries and regions around the world have introduced menu labelling on a voluntary or mandatory basis [23-27]. Similarly, a number of workplace and healthcare organisations around the world have independently developed and implemented menu labelling policies at national and local levels [28-30]. As the momentum to implement menu labelling policies has increased, issues relating to implementation have arisen. Challenges relate to delays in legislation implementation [31], lack of monitoring/enforcement [32], poor uptake by food service businesses [33, 34] and inaccurate nutritional information being presented on menus due to cited reasons such as inconsistent portioning, lack of training and difficulties in sourcing nutrition information [32, 35-37]. It is evident that the process involved in the development and implementation of labelling policies is context-specific, non-linear and shaped by many different actors and factors [38].

Most reviews have examined the effectiveness of menu labelling $[21,22]$, and despite evidence of implementation issues, no previous review has focused on the challenges facing the key actors responsible for adopting this intervention, the food service industry. To help systematically evaluate the determinants of implementation, the Consolidated Framework for Implementation Research (CFIR) was chosen as the a priori framework as it incorporates constructs from 19 implementation theories, frameworks and models into one single comprehensive framework [39]. Identification of barriers and facilitators (i.e. determinants) guided by an established framework will provide a foundation to select and tailor implementation strategies to improve adoption, implementation, sustainment, and scale-up of menu labelling interventions [40]. Moreover, the review will explore the relationships between determinants to assist with understanding the mechanisms underpinning the implementation of menu labelling interventions. In using the 'best fit' framework synthesis approach [41], an adapted CFIR framework will be developed which goes beyond listing determinants to illustrate the relationships between factors. This approach, adopted by other recently published reviews [42-45], may help advance the a priori framework towards being more testable. For example, the adapted CFIR framework can be used to generate a hypothesis, specifically in the context of menu labelling, to be tested in empirical research. 


\section{Objectives}

The review objectives were to (1) synthesise existing research on the perceived barriers and facilitators to implementation of menu labelling interventions from the perspective of the food service industry, (2) map these determinants to the CFIR constructs, (3) in instances where data does not fit the CFIR, to generate new constructs and themes, (4) identify relationships between a priori and new constructs, and (5) develop an adapted framework based on the review findings.

\section{Methods}

The protocol, published elsewhere [46], is summarised briefly here. The review was conducted according to Preferred Reporting Items for Systematic Reviews and MetaAnalyses (PRISMA) guidelines [47] (see Additional file 1) and registered with PROSPERO, the International Prospective Register of Systematic Reviews (CRD42017083 306). The review followed the steps of the 'best fit' framework synthesis approach [41], which starts with identification of a pre-existing framework to be used for initial coding of data which is then updated in response to the emerging synthesis, thus creating an adapted framework. This approach is described in detail in the published protocol [46].

\section{Conceptual framework}

The CFIR is a meta-theoretical framework composed of 39 constructs under five major domains: (1) intervention characteristics, (2) outer setting, (3) inner setting, (4) individual characteristics, and (5) process [39]. The CFIR has a strong emphasis on contextual determinants, with three of the five domains (i.e. process, inner setting and outer setting) capturing contextual factors operating at multiple levels (i.e. micro, meso and macro level) [48]. The CFIR provides a common language and clear consensual definitions which allows for comparison across diverse studies $[49,50]$.

\section{Eligibility and search criteria}

The criteria for study eligibility are summarised in Table 1. All primary research studies using qualitative, quantitative or mixed methods approaches were eligible for inclusion. As per the protocol [46], we had initially planned to include supply-side stakeholders (direct and indirect) with a role in implementation of menu labelling interventions; however, we decided to narrow the population of interest to direct supply-side stakeholders only (i.e. food service staff and management). These direct supply-side stakeholders are responsible for the initial decision to adopt/implement menu labelling interventions, and thus need to be targeted first to ensure adoption, implementation, sustainment, and scale-up of menu labelling interventions.

PubMed, EMBASE, CINAHL, PsycINFO, Web of Science and Scopus electronic databases were searched. Grey literature were sourced from: Google Scholar, OpenGrey, RIAN, EThOS, ProQuest, WorldCat, Networked Digital Library of Theses and Dissertations, Open Access Theses and Dissertations, and public health organisation websites. The search included studies up until February 2018. The search strategy is presented in Additional file 2. Screening reference lists, citation chaining and contacting authors of all included studies were undertaken.

\section{Study selection and appraisal}

At least two independent reviewers ( $\mathrm{CK}, \mathrm{CH}$, SS, CKelly, FG) conducted the study selection process (i.e. title and abstract screening followed by full text articles). The quality of the included studies were assessed by two independent reviewers (CK, JMS) using the Mixed Methods Appraisal Tool (MMAT) [51]. Reviewers resolved discrepancies through discussion and consensus. No studies were excluded based on quality scores; the quality cut-off points outlined in Appendix 6 were used as part of the sensitivity analysis to explore whether studies with different quality scores affected the presence of any constructs or domains in the adapted framework [52].

Table 1 Study eligibility criteria

\begin{tabular}{ll}
\hline Inclusion criteria & Exclusion criteria \\
\hline $\begin{array}{l}\text { Population: direct supply-side stakeholders with a role in menu } \\
\text { labelling implementation (e.g. food service business staff and }\end{array}$ & $\begin{array}{l}\text { Population: demand side stakeholders (e.g. consumers) and } \\
\text { management, caterers). }\end{array}$ \\
$\begin{array}{l}\text { Intervention: no restriction on menu labelling format (numeric } \\
\text { or interpretive), scheme (voluntary or mandatory) or type of }\end{array}$ & Intervention: menu labelling as part of a multi-component \\
food service business. & intervention. \\
$\begin{array}{l}\text { Type of research: all primary research studies (from grey or } \\
\text { peer-reviewed literature) using qualitative, quantitative or }\end{array}$ & Type of research: editorials, commentary and opinion pieces. \\
mixed methods approaches. & \\
Language and publication year: no restrictions. & \\
Outcome: any barrier or facilitator to the implementation of & \\
menu labelling interventions. &
\end{tabular}




\section{Data extraction and synthesis}

Two independent reviewers (CK, JMS) extracted data from all included studies (see Additional file 3 for data extraction form). Upon reaching consensus on data extracted, the synthesis was initiated (Fig. 1). Data synthesis was led by one reviewer (CK) using a mix of deductive and inductive analysis techniques, with regular consultation with review team members (SMH, CMR, CKelly) through a consensus decision making process $[53,54]$. As the intervention (i.e. menu labelling) was predominantly targeted at settings outside of healthcare, the first step involved developing a codebook in which the CFIR constructs were operationalised and adapted. Deductive coding using the CFIR codebook was an iterative process, which required familiarisation with the data. Any resulting modifications to construct definitions were discussed with review team members until consensus was reached (see Additional file 4 for final codebook). Secondly, inductive coding was used to develop themes within broadly-defined CFIR constructs to capture the detail of the barrier or enabler in the context of menu labelling. Similarly, in instances where data did not fit existing
CFIR constructs, thematic analysis was performed [55]. Findings were clustered and synthesised into a final set of constructs and themes representing the whole dataset.

A member of the analysis team (CMR) is from the CFIR development group and provided expert input on CFIR construct definitions during the deductive coding. Other quality checks included double-coding a sub-set of four papers (CK, CKelly), a review of constructs and supporting data following the deductive coding (CK, $\mathrm{CMR}, \mathrm{SMH}$ ) and a review of data that did not fit existing CFIR constructs and new constructs generated following the inductive coding (CK, CKelly, CMR, SMH). No estimates of inter-rater reliability were calculated.

Barriers and facilitators (coded to constructs) were rank-ordered according to the frequency of studies that reported them to identify the most common determinants to menu labelling implementation. In addition, review team members (CK, CMR, SMH) examined the relationships between constructs based on data from the primary research studies. These relationships were based on the results of the primary studies, i.e., the authors of the primary studies reported relationships based on their

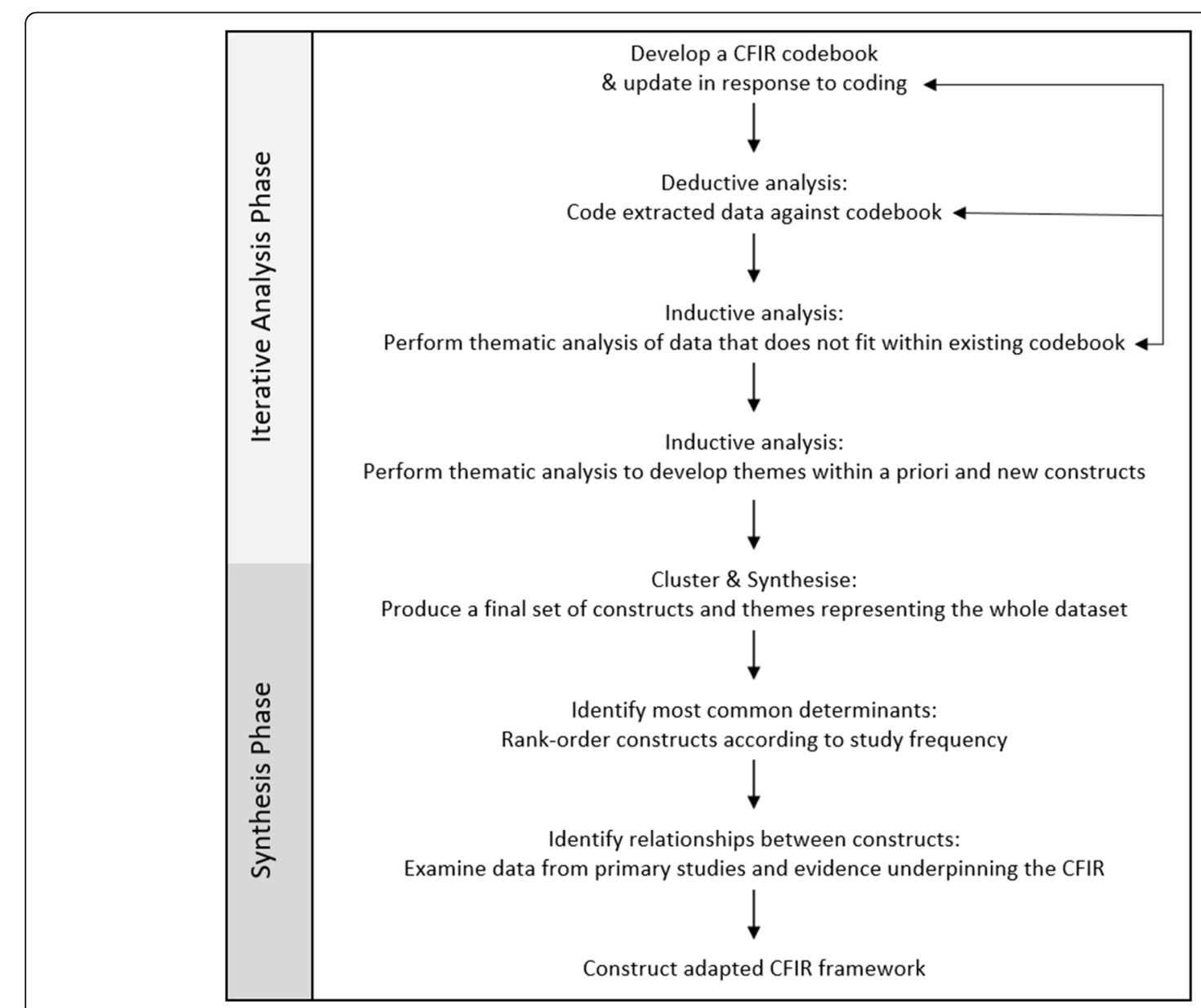

Fig. 1 Flow diagram of data analysis and synthesis process 
analysis of the raw data. All relationships were captured, regardless of study type, and given equal weight. In addition, a review of theories, frameworks and models underpinning the CFIR was undertaken to examine relationships between constructs/domains. The results of the coding and analysis of relationships informed the construction of an adapted CFIR framework of the implementation determinants for menu labelling interventions. The depiction of the adapted framework (as a figure) was guided by input from review team members (CK, SMH, CH, CKelly) and reviewed by all members of the team until consensus was reached.

\section{Testing the synthesis}

Following the construction of an adapted CFIR framework, one reviewer $(\mathrm{CK})$ assessed the potential for bias by examining differences between the a priori and adapted framework, and seeking evidence of negative cases, and conducted a sensitivity analysis to determine if the synthesis was sensitive to study methodology, quality and location [41].

\section{Results}

\section{Study selection}

The search yielded a total of 2806 records, after duplicates were removed. Following title and abstract review, 47 records (representing 39 distinct studies) were included in the full-text review. In instances where two or more records represented the same study, the record with the most data reported was used; except in the case of two records (peer-reviewed article in English and dissertation in Portuguese) representing one study, the less comprehensive dataset available in English was selected to avoid issues with language translation. Following fulltext review, 17 studies were included (Fig. 2).

\section{Study characteristics and quality appraisal}

Study characteristics are provided in Additional file 5 . Included studies were largely based in developed countries $(n=15)$. Studies used mostly quantitative data collection methods $(n=8)$, followed by qualitative $(n=7)$ and mixed methods $(n=2)$. Only two studies used an explicit theory and in both instances, the Diffusion of Innovation Theory $[56,57]$. The study setting ranged

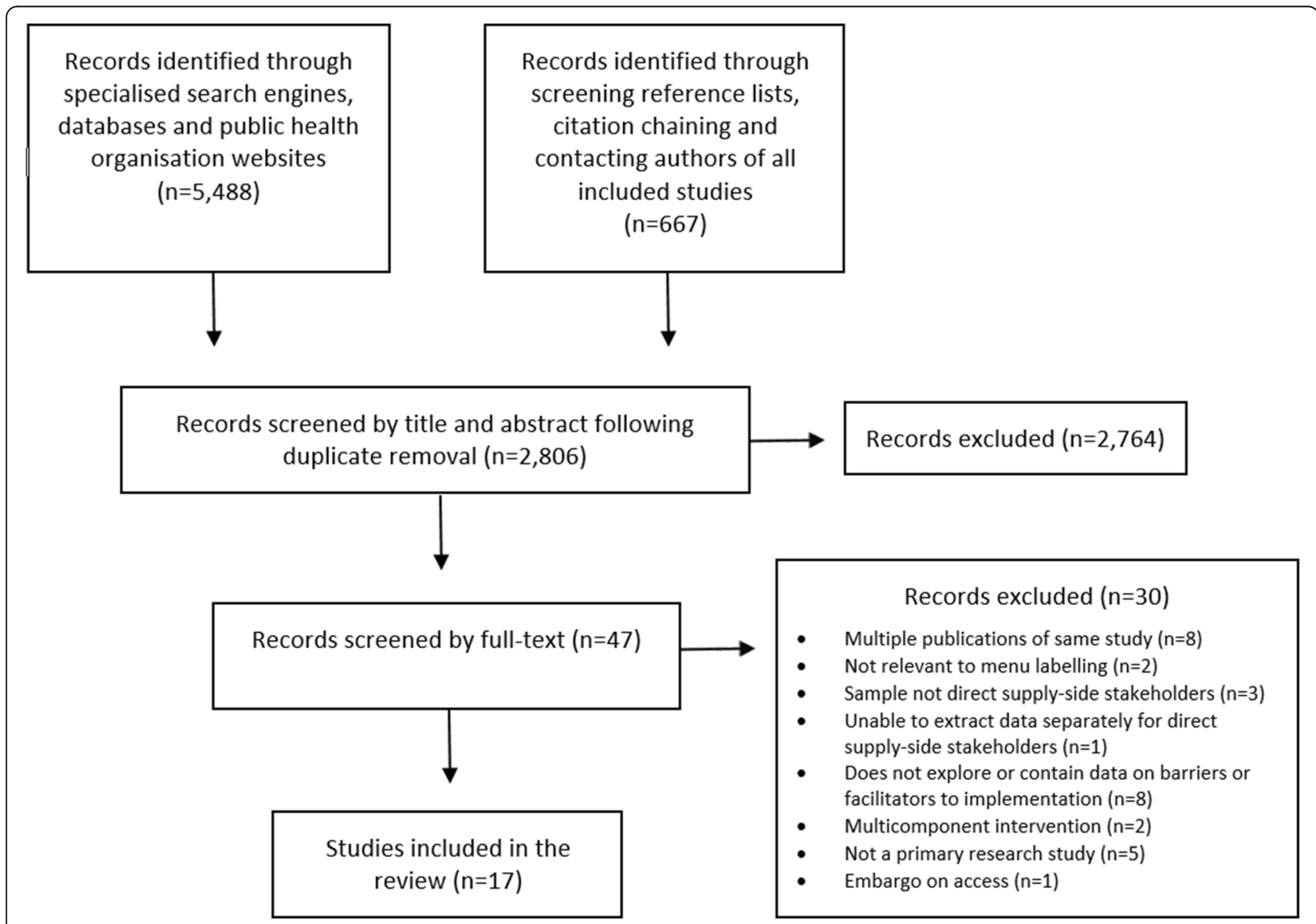

Fig. 2 PRISMA flow diagram of study selection process 
from small independently owned restaurants to large foodservice corporations including chain and franchise restaurants, as well as large catering companies. Menu labelling schemes were predominately voluntary $(n=16)$, with one study including both voluntary and mandatory schemes [58]. Most studies assessed both pre- and postimplementation of menu labelling $(n=9)$, while the remaining studies examined pre-implementation $(n=3)$ and post-implementation $(n=5)$. In terms of study quality, the majority of studies were rated as average quality $(n=10)$. Additional file 6 presents a detailed breakdown of the quality assessment for each study.

\section{Barriers and facilitators}

A summary of perceived barriers and facilitators coded to the CFIR constructs, including constructs with no supporting data, are presented in Table 2. New constructs generated inductively from the data, that did not align with existing CFIR constructs, are presented in Table 3 (see definitions and eligibility criteria in Additional file 4). While some a priori and new constructs manifested as either barriers or facilitators to implementation, others acted simultaneously as barriers and facilitators (e.g. increased consumer demand for menu labelling or the lack thereof). Additional file 7 provides more detailed results, including themes with references under each construct and illustrative quotes. A narrative summary of frequently cited perceived barriers and facilitators (i.e. those discussed in 10 or more of the included studies) is presented below.

\section{Barriers}

The most commonly reported barriers to implementation were coded to the CFIR constructs "Implementation Climate" (14/17) and "Consumer Needs and Resources" (13/17). More specifically, within the construct "Implementation Climate", frequently reported barriers were coded to the sub-construct "Compatibility" (12/17). Barriers relating to "Compatibility" (i.e. compatibility with organisation work processes) included lack of standardised recipes/menus, limited space on menus, frequent menu changes/variations, too many products/menu items, no sense of responsibility, lack of alignment with food served/aesthetics, fast-paced environment and lack of mass-produced food. Barriers relating to "Consumer Needs and Resources" (i.e. consumer needs and preferences) included lack of customer demand for/interest in menu labelling, risk of overwhelmed/confused customers and interference with customer dining experience.

Other frequently reported barriers were coded to the CFIR constructs "Cost" (12/17), "Relative Advantage" (11/17) and "External Policies and Incentives" (12/17). Barriers relating to "Cost" (i.e. cost of the intervention) included the general cost of menu labelling, nutritional analysis, changing menu/displays, printing nutrition information, hiring consultants/appointing advisors, purchasing nutrition analysis software, staff time in implementation and finally, the cost of training staff. Barriers relating to "Relative Advantage" (i.e. (dis) advantage of implementing intervention compared to alternative) included reduced sales/profitability, loss of flexibility/creativity, customer loss, negative impact on image/brand and lack of economic return on time investment. Barriers relating to "External Policies and Incentives" (i.e. external policies to spread intervention) included absence of legislation, lack of monitoring and enforcement, lack of guidelines, fears of liability due to inaccurate information and perceived excessive bureaucratic burdens on businesses.

Frequently reported barriers were also coded to the CFIR construct "Readiness for Implementation" (12/17). Under "Readiness for Implementation", commonly reported barriers were coded to the sub-constructs "Available Resources" (10/17) and "Access to Knowledge and Information" (10/17). Barriers relating to "Available Resources" (i.e. available resources within the organisation) included lack of time, lack of money, limited staff and short-term building lease. Barriers relating to "Access to Knowledge and Information" (i.e. access to knowledge and information about the intervention) within the implementing food service business included lack of nutrition expertise in the organisation, challenges in acquiring nutrition information, lack of reliable nutrition information, lack of training and support, lack of nutrition analysis software and difficulties with business systems. There were also barriers to 'accessing knowledge and information' from agencies external to the food service businesses, which included difficulty in obtaining information from suppliers/health agencies, discrepancy in nutrition information obtained from suppliers and excessive information provided by health agencies.

\section{Facilitators}

The most commonly reported facilitators were coded to the CFIR constructs "Relative Advantage" of menu labelling (15/17) and "Consumer Needs and Resources" (12/17). Facilitators relating to "Relative Advantage" included perceived benefits of menu labelling for participating businesses, improved business image/reputation, attracting/ retaining customers, increased sales/profitability, cost saving, increased customer trust/confidence, opportunity for better customer service, opportunity for creativity/learning, menu labelling as a marketing tool, building relationships with health authorities. Facilitators relating to "Consumer Needs and Resources" included consumer demand for/ interest in menu labelling, providing nutrition information to customers, enabling informed food choices, providing a consistent menu labelling scheme for customers and improving customer health. 
Table 2 Summary of perceived barriers and facilitators to implementation of menu labelling coded to the CFIR

\begin{tabular}{|c|c|c|c|c|}
\hline CFIR domain & CFIR construct & CFIR sub-construct & $\begin{array}{l}\text { Studies that identified } \\
\text { facilitators }\end{array}$ & $\begin{array}{l}\text { Studies that identified } \\
\text { barriers }\end{array}$ \\
\hline \multirow{8}{*}{$\begin{array}{l}\text { Intervention } \\
\text { Characteristics }\end{array}$} & Intervention source & & [59-61] & No data \\
\hline & Evidence strength and quality & & {$[62,63]$} & {$[62,64,65]$} \\
\hline & Relative advantage & & [56-70] & {$[59,61-65,67-71]$} \\
\hline & Adaptability & & No data & No data \\
\hline & Trialability & & No data & No data \\
\hline & Complexity & & No data & {$[59-63,65,70,71]$} \\
\hline & Design quality and packaging & & {$[63,67]$} & {$[59,61,65,68]$} \\
\hline & Cost & & [61] & {$[58,59,61-66,68,69,71,72]$} \\
\hline \multirow[t]{4}{*}{ Outer Setting } & Consumer needs and resources & & {$[57-65,67,68,72]$} & {$[57-68,70,71]$} \\
\hline & Cosmopolitanism & & {$[59,61]$} & No data \\
\hline & Peer pressure & & {$[57-61,63,64,67]$} & [61] \\
\hline & External policy and incentives & & {$[56,58-63,67,68]$} & {$[58,59,61-66,68-71]$} \\
\hline \multirow[t]{14}{*}{ Inner Setting } & Structural characteristics & & {$[57,61,63-65]$} & {$[60-63,65,66]$} \\
\hline & Networks and communications & & [70] & No data \\
\hline & Culture & & No data & No data \\
\hline & Implementation climate & & & \\
\hline & & Tension for change & No data & {$[61,62,65,68,71]$} \\
\hline & & Compatibility & {$[58-64,69,71]$} & {$[58-66,69-71]$} \\
\hline & & Relative priority & No data & {$[60-64,71]$} \\
\hline & & Incentives and rewards & No data & [62] \\
\hline & & Goals and feedback & {$[58,61,69]$} & {$[59,61,62,64,67-71]$} \\
\hline & & Learning climate & No data & No data \\
\hline & Readiness for implementation & & & \\
\hline & & Leadership support & {$[61,62]$} & No data \\
\hline & & Available resources & {$[62,63,65]$} & {$[58-63,65,68,69,71]$} \\
\hline & & $\begin{array}{l}\text { Access to knowledge } \\
\text { and information }\end{array}$ & {$[57,59-63,65-67,70]$} & {$[58-63,66,69,71,72]$} \\
\hline \multirow{5}{*}{$\begin{array}{l}\text { Characteristics } \\
\text { of Individuals }\end{array}$} & Knowledge and beliefs & & {$[61,63,67]$} & {$[60,62,65,69,71,72]$} \\
\hline & Self-efficacy & & No data & No data \\
\hline & Individual stage of change & & No data & No data \\
\hline & Individual identification with food business & & No data & No data \\
\hline & Other personal attributes & & [71] & {$[60,71]$} \\
\hline \multirow[t]{8}{*}{ Process } & Planning & & No data & No data \\
\hline & Engaging & & [63] & No data \\
\hline & & Opinion leaders & [59] & No data \\
\hline & & $\begin{array}{l}\text { Formally appointed } \\
\text { internal implementation } \\
\text { leaders }\end{array}$ & No data & No data \\
\hline & & Champions & No data & No data \\
\hline & & External change agents & {$[59-63,65,67]$} & {$[60,61,63]$} \\
\hline & Executing & & No data & {$[58,61,62]$} \\
\hline & Reflecting and evaluating & & [56] & No data \\
\hline
\end{tabular}


Table 3 Summary of new constructs generated inductively from the data

\begin{tabular}{|c|c|c|c|}
\hline CFIR domain & New construct & Studies that identified facilitators & Studies that identified barriers \\
\hline \multirow[t]{3}{*}{ Outer Setting } & Media \& societal pressure & {$[58,67]$} & No data \\
\hline & Economic climate & No data & {$[62,63,65]$} \\
\hline & Educational system & {$[61,63]$} & No data \\
\hline \multirow[t]{6}{*}{ Process } & Engaging: internal key stakeholders & [59] & {$[59,61-63,69,71]$} \\
\hline & Engaging: external key stakeholders & {$[63,65]$} & {$[59-63,69,71]$} \\
\hline & Adapting the organisation & {$[61,63,70]$} & No data \\
\hline & Adapting the intervention & {$[59,61,62,65,67,68,70,71]$} & No data \\
\hline & Trialing & [63] & No data \\
\hline & Scaling up & {$[59,63]$} & No data \\
\hline
\end{tabular}

Frequently cited facilitators were also coded to the CFIR construct "Readiness for Implementation" (10/17). More specifically, within the construct "Readiness for Implementation", frequently reported facilitators were coded to the sub-construct "Access to Knowledge and Information" (10/17). Facilitators relating to "Access to Knowledge and Information" within the implementing food service business included staff training and support, access to information, access to (user-friendly) nutrition analysis software and access to an in-house technician. There were also facilitators to 'accessing knowledge and information' from agencies external to the food service businesses, which included access to knowledge and information from designers/professionals/health agencies/ suppliers, access to user-friendly (approved) nutrition analysis software from health agencies and access to training from professionals/health agencies.

\section{Construct relationships}

Relationships between constructs, within and/or across domains, were evident in 14 out of 17 studies; where one or more constructs facilitated and/or hindered one or more additional constructs. For example, being part of a large franchise (i.e. "Structural Characteristics") facilitated access to standardised recipes and information (i.e. "Compatibility" and "Access to Knowledge and Information") [63] . In 5 out of 17 studies, there was a relationship between the barriers encountered and the way the intervention was tailored or may be tailored for future scale. For example, in response to liability concerns due to inaccurate nutritional information (i.e. "External Policy and Incentives"), businesses included a caveat on their menus stating reasons for possible variation from stated values (i.e. "Adapting the Intervention") [59]. Another example includes a perceived lack of consumer knowledge and non-user friendly menu labels (i.e. "Consumer Needs and Resources" and "Design Quality and Packaging) which led businesses to recommend a consumer education campaign to be rolled out alongside future menu labelling interventions (i.e. "Adapting the
Intervention"). For more detailed information on construct relationships, including illustrative quotes and reference studies, see Additional file 8.

\section{Framework revision}

The adapted framework maintained many of the elements of the CFIR but a number of (sub) constructs with no supporting data were removed and newly developed constructs incorporated. For clarity and ease of understanding, the barriers and facilitators to implementation of menu labelling interventions are illustrated separately in Figs. 3 and 4, respectively. The adapted framework, consisting of the five original CFIR domains, also illustrates the relationship between these domains; three domains (i.e. "Intervention Characteristics", "Individual Characteristics" and "Process") are nested within the "Organisation Characteristics" domain, while the "Organisation Characteristics" is nested within the "Outer Setting" domain. This depiction reflects the influence of the external context (e.g. legislation, economy, consumers) on the internal setting of food service businesses (e.g. ways of working, perception of importance of implementing menu labelling) and subsequently, their contribution to shaping positive or negative perceptions of the menu labelling intervention itself (e.g. perceived benefits of menu labelling compared to an alternative), the individuals involved in implementation (e.g. their knowledge and beliefs about menu labelling) and the process involved in implementation (e.g. refining workflows to accommodate menu labelling, engaging relevant stakeholders).

\section{Sensitivity analysis}

Sensitivity analysis showed the adapted framework was sensitive to a number of factors including study methodology, quality and study location. While all overarching domains were not sensitive to study methodology or quality, the following domains were sensitive to study location: "Inner Setting", "Characteristics of Individuals" and "Process" (illustrated in Figs. 3 and 4). None of these domains contained all eight categories of study location. Constructs common to all study locations included: 


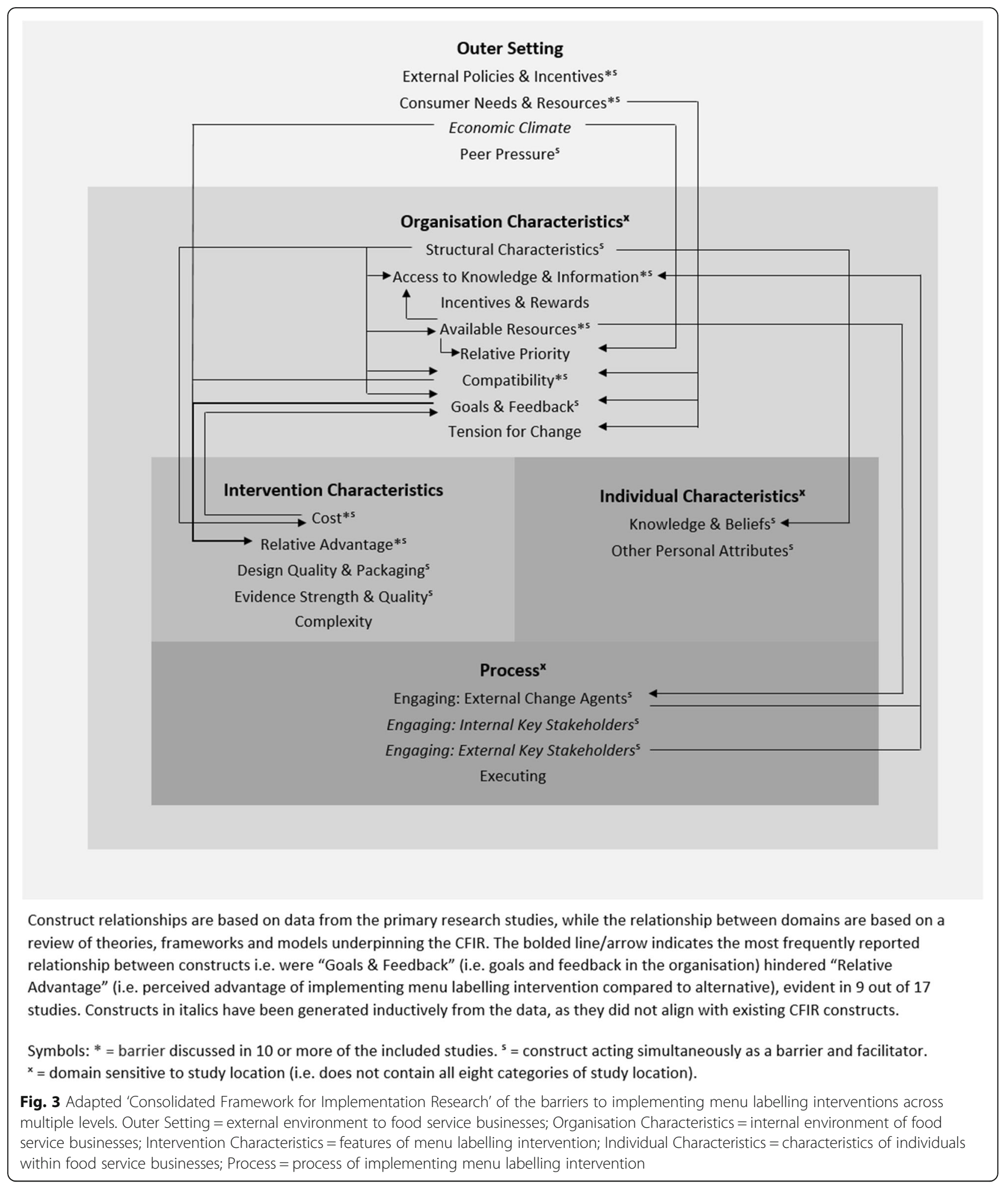

"Relative Advantage", "Consumer Needs \& Resources" and "External Policy \& Incentives". For more detailed results of the sensitivity analysis, see Additional file 9. No constructs or domains were removed from the adapted framework based on the sensitivity analysis undertaken.

\section{Discussion}

The review identified a range of perceived barriers and facilitators to implementation of menu labelling interventions, using an existing conceptual implementation framework (i.e. the CFIR) [39]. Factors influencing 


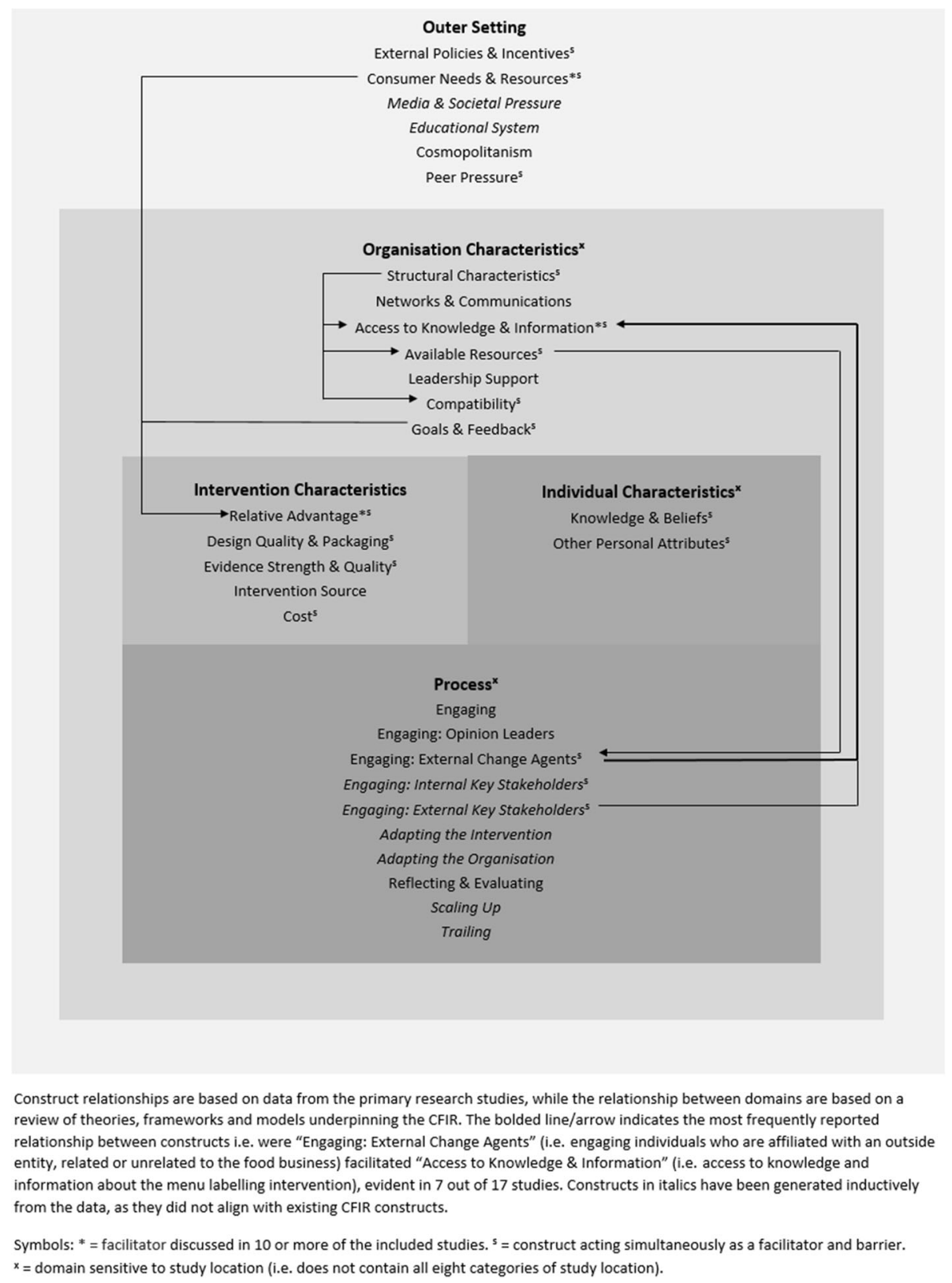

Fig. 4 Adapted 'Consolidated Framework for Implementation Research' of the facilitators to implementing menu labelling interventions across multiple levels. Outer Setting = external environment to food service businesses; Organisation Characteristics = internal environment of food service businesses; Intervention Characteristics = features of menu labelling intervention; Individual Characteristics = characteristics of individuals within food service businesses; Process = process of implementing menu labelling intervention

implementation were predominantly related to key characteristics of the menu labelling intervention as well as factors operating within the inner setting of food service businesses and external context of food service businesses. Multiple cases of dissonance (i.e. contradictory views) were also evident in the review findings, with many a priori and new constructs acting simultaneously as barriers and facilitators. Furthermore, interrelationships between constructs within and across domains were also evident, highlighting the complex and dynamic influences at play during implementation. A key output of the review was an adapted framework which was constructed to illustrate how factors interact to influence implementation effectiveness of menu labelling interventions.

The structure of the adapted framework (Figs. 3 \& 4) somewhat reflects some of the theories/models underpinning the CFIR [73-76] as well as key organisational theories [77]. These theories/models highlight the influence of the 
complex interaction between organisations and their environment. In particular, organisational theories highlight that optimal conditions in the internal setting of organisations can be undermined by changes in the organisations' external environment [78-82]. Moreover, policy implementation research has emphasised the inherent interdependency between factors as well as the crucial importance of context [83]. In the adapted framework, the food service business is embedded in their external environment to reflect the interaction between both. Nested within the food service business includes characteristics of individuals involved, features of the menu labelling intervention and the process of implementation. This structure confirms prior research and theory that implementation success is influenced by multi-level contextual factors (i.e. individual, organisational and system-level factors) $[48,83]$.

The findings of this review echo propositions of organisational theories which suggest implementation is more likely to occur if innovations promote organisational survival [77, 84]. For example, organisations will implement innovations to comply with accrediting bodies [85], to respond to changing patient needs [86] and to offer a valuable service to patients [87]. Similarly, in an effort to promote survival, organisations will minimise costs; adhere to norms, values and expectations adopted by institutions in their environment; develop characteristics that differentiate them from competitors; and acquire/maintain resources and autonomy [84]. In this review, frequently cited factors influencing menu labelling implementation were coded to the CFIR (sub)constructs: "External Policy and Incentives", "Consumer Needs and Resources", "Peer Pressure", "Compatibility", "Available Resources", "Relative Advantage" and "Cost".

Many theories underpinning the CFIR have focused on implementation of clinical innovations in healthcare and mental health settings; thus, the application of the CFIR to a public health intervention (i.e. menu labelling) in the food service setting may explain the absence of a priori constructs in the data and the addition of new constructs. In particular, constructs under the "Characteristics of Individuals" domain were infrequently coded. This may be due to CFIR's predominate focus on determinants of implementation at organisation and system levels rather than individual level. Thus, the CFIR may not provide sufficient individual-level constructs and operationalisation of these to assist with coding. Newly developed constructs that were frequently coded (i.e. "Engaging: internal key stakeholders" and "Engaging: external key stakeholders") are in line with proposed changes for the second version of the CFIR, which will include the sub-construct "Engaging: key stakeholders" under the "Process" domain [88].

\section{Implications and recommendations for practice, policy, and research}

Our identification of the influential factors in the implementation of menu labelling can help guide policy/ decision makers in selecting and tailoring implementation strategies [40, 89]. The Expert Recommendations for Implementing Change (ERIC) project provides a taxonomy of discrete implementation strategies that can be used in isolation or in combination to target factors influencing implementation at different levels [90]. More recently, the CFIR-ERIC Implementation Strategy Matching Tool has been developed to match ERIC implementation strategies to address CFIR-based barriers [91]. Despite being a useful starting point, this tool should be used with caution due to the lack of consensus on which ERIC strategies best address CFIR-based contextual barriers [91]. Nevertheless, the tool can be used alongside implementation mapping [92], a systematic and rigorous approach based on intervention mapping [93, 94], to help further develop or identify strategies to address contextual determinants of menu labelling implementation.

One strategy recommended by food businesses is the development of a convincing business case for menu labelling, framing the 'relative advantage' of menu labelling in order to attract food businesses [63]. Studies suggest food businesses are willing to overcome perceived barriers (e.g. cost, standardising recipes) in order to obtain the perceived benefits (e.g. improved business image, attracting customers) $[60,61,63]$. Moreover, there are potential cost-saving implications from menu labelling (via removing ingredients and standardising recipes/ serving sizes) that may attract food businesses [60, 63]. While research shows menu labelling effects consumer behaviour [21, 22], the review findings suggest food businesses rely more on evidence from consumers/business activity than scientific research. Despite their being evidence of public support for menu labelling [64, 65, 95], further efforts are required to engage consumers in order to increase uptake and demand (e.g. through consumer education mass media campaigns) [96, 97].

In the review, a commonly reported facilitator and recommendation was that of adaptation. Food businesses adapted or recommended adapting the menu labelling intervention to help overcome perceived barriers (e.g. lack of consumer understanding, limited space on menus). While adaptation can be viewed as a key step in the implementation process [98, 99], the risk of compromising fidelity to core intervention components and potentially reducing the effects needs to be considered [100]. Few of the included studies adequately reported on the intervention components of their menu labelling scheme; thus future studies should report on same using the TIDieR-PHP checklist [101]. Moreover, research should investigate how menu labelling interventions can be effectively adapted to different contexts (e.g. large chain versus small independently-owned restaurants) without jeopardising core intervention components and effect size. 
Another prominent barrier and facilitator was that of policy/legislation relating to menu labelling. Food businesses reported adopting menu labelling in response to mandatory schemes, but not in the absence of same. This finding is in line with key propositions of institutional theory, which suggest organisations will implement an innovation in response to coercion or strong pressure to comply with rules, mandates or regulations [102]. While it is recognised that regulation is required to advance public health $[19,38,103]$, the risk of tokenism, that is the superficial implementation of menu labelling, in response to regulation needs to be averted [102]. In the absence of monitoring and enforcement, food businesses may present inaccurate nutrition information on menus [32]. This highlights the need for effective mechanisms to be put in place to ensure rigorous enforcement alongside regulation [32, 104].

Future studies should determine the phase of implementation relevant to different factors. Few implementation models/frameworks, including the CFIR [39], recognise that different factors may influence implementation at different points in the implementation process [105]. Such research may help identify factors which manifest or present more prominently at different stages of implementation allowing stakeholders to anticipate and address factors in sequence or in tandem for effective implementation.

Future research should investigate the relationships between the determinants. To date, many implementation studies have assessed determinants individually, assuming a linear relationship between the determinants and the outcomes [106]. However, there may be a synergistic negative effect between two seemingly minor barriers which constitute an important obstacle to effective implementation when they interact [106]. Moreover, the nature of the relationship should be examined in future studies. For example, interrelationships between factors may break down into more specific types of relationships (e.g. leverages/mitigates, engages/disengages). Future research should also assess the relative importance of determinants and relationships. Furthermore, this first review of the evidence is a starting point from which researchers can test relationships and refine the proposed adapted framework.

Finally, this review adopted a bottom-up policy implementation perspective by focusing on the views of direct supply-side stakeholders (i.e. food service staff and management), a decision based on this group being key stakeholders in the decision to adopt/implement menu labelling [83]. According to public health advocates, industry actors should not be involved in nutrition policy development due to concerns over conflict of interest; however, they should be involved during implementation $[38,97,103,104]$. Interestingly, findings from this review suggest intervention source was not a perceived barrier to implementation, but a facilitator in a limited number of studies. As implementation of food policies (such as menu labelling) are influenced by multiple actors and factors, future research should consider the perspective of indirect supply-side stakeholders (i.e. policy-makers, researchers, public health professionals, food suppliers) as well as demand-side stakeholders (i.e. consumers).

\section{Limitations}

Despite using comprehensive and rigorous methods in this review, there were limitations that must be acknowledged. Firstly, most of the included studies were crosssectional; therefore, we cannot state with certainty the factors that represent the most important influence. Moreover, the relative importance of different factors and relationships is likely to be context dependent. The review found heterogeneity in terms of study setting, ranging from small independently owned restaurants to large foodservice corporations including chain and franchise restaurants, as well as large catering companies. The review also showed many a priori and new constructs acted simultaneously as barriers and facilitators, which highlights heterogeneity in the findings. Secondly, determinants of implementation were often assessed individually in the included studies; thus, (implicitly) assuming a linear relationship between the determinants and the outcomes. Therefore, the full extent of relationships between individual barriers and facilitators may not be captured in the primary studies. Thirdly, the majority of studies used questionnaires/surveys which are subject to bias due to the researcher's selection of determinants and so studies may not have captured all relevant barriers and facilitators. Fourthly, included studies often failed to distinguish between actual barriers and facilitators experienced and those perceived to exist. The review findings may place equal importance on all determinants, although perceived importance of particular factors may not correspond with actual importance. Finally, despite undertaking and reporting on quality appraisal and a sensitivity analysis, all studies were synthesised equally in order to provide a literature summary. Therefore, evidence from studies may have been given undue weight and others underemphasised.

\section{Conclusion}

This systematic review generates an adapted CFIR framework for understanding implementation of menu labelling interventions. The adapted framework highlights that implementation of menu labelling is influenced by multiple interdependent factors, particularly related to the external context of food businesses (e.g. consumers, legislation), internal setting of food businesses (e.g. compatibility, available information and resources) and features of the menu labelling intervention (e.g. perceived benefits, cost). The findings can be used by researchers and practitioners to 
develop, select, tailor and test strategies to address barriers that impede implementation and to leverage facilitators that assist with implementation effort. Future research should build on this work in order to assess the relative importance of determinants and relationships.

\section{Supplementary information}

Supplementary information accompanies this paper at https://doi.org/10. 1186/s12966-020-00948-1.

Additional file 1. PRISMA (Preferred Reporting Items for Systematic Reviews and Meta-Analyses) 2009 checklist. This file provides a completed PRISMA 2009 checklist.

Additional file 2. Review search strategy. This file provides the search strategy used in this review.

Additional file 3. Standardised data extraction form. This file provides the data extraction form used in this review.

Additional file 4. Final codebook and coding assumptions. This file provides the final codebook and coding assumptions used in this review.

Additional file 5. Characteristics of included studies. This file provides information on the characteristics of included studies in this review.

Additional file 6. Quality assessment of each study using MMAT criteria. This file provides a detailed breakdown of the quality assessment for each study.

Additional file 7. List of constructs and sample quotes following the deductive and inductive coding. This file provides results from the deductive and inductive coding, including themes under each construct and illustrative quotes.

Additional file 8. Construct relationships. This file provides information on construct relationships and recommendations, including illustrative quotes.

Additional file 9. Sensitivity analysis results for each construct. This file provides results of the sensitivity analysis.

\section{Abbreviations}

CFIR: Consolidated Framework for Implementation Research; ERIC: Expert Recommendations for Implementing Change; MMAT: Mixed Methods Appraisal Tool; NCDs: Non-communicable diseases; PRISMA: Preferred Reporting Items for Systematic Reviews and Meta-Analyses

\section{Acknowledgments}

We are grateful to Dr. Laura Damschroder for her helpful feedback on queries relating to CFIR construct definitions. We also wish to acknowledge the contributions of the Healthy Eating Active Living Policy Priority Programme as part of Health \& Wellbeing, Strategic Planning and Transformation of the Health Service Executive in Ireland, for their input to the design of this study.

\section{Authors' contributions}

$\mathrm{CK}$, with guidance from CKelly, designed and conducted the literature search. CK, CKelly, CH, FG and SS conducted the study selection process. CK undertook screening of the reference lists, citation chaining and contacting authors of all included studies. CK and JMS were involved in data extraction and quality appraisal of all included studies. Data synthesis was led by CK with regular consultation with SMH, CMR and CKelly. Relationships between constructs were identified by $\mathrm{CK}, \mathrm{CMR}$ and $\mathrm{SMH}$. Construction of the adapted framework was led by $\mathrm{CK}$ with guidance from $\mathrm{SMH}, \mathrm{CH}$ and CKelly. Testing the synthesis was undertaken by CK. The first draft of the manuscript was completed by CK, with critical review and feedback on subsequent drafts from all review team members. All authors read and approved the final manuscript.

\section{Funding}

This research is funded by the Health Research Board SPHeRE/2013/1.
Availability of data and materials

Not applicable

Ethics approval and consent to participate

Not applicable.

\section{Consent for publication}

Not applicable

\section{Competing interests}

The authors declare that they have no competing interests.

\section{Author details}

'Discipline of Health Promotion, School of Health Sciences, National University of Ireland Galway, University Road, Galway, Ireland. ${ }^{2}$ School of Public Health, University College Cork, College Road, Cork, Ireland. ${ }^{3}$ Health Behaviour Change Research Group, School of Psychology, National University of Ireland Galway, University Road, Galway, Ireland. ${ }^{4}$ Ann Arbor VA Center for Clinical Management Research, P.O. Box 130170, Ann Arbor, Ml 48113-0170, USA. ${ }^{5}$ Discipline of Public Health and Primary Care, Institute of Population Health, Trinity College Dublin Russell Centre, Tallaght Cross, Dublin 24, Ireland. ${ }^{6}$ National Institute for Prevention and Cardiovascular Health, Croí Heart and Stroke Centre, Moyola Lane, Newcastle, Galway, Ireland.

Received: 10 July 2019 Accepted: 23 March 2020

Published online: 15 April 2020

\section{References}

1. Adams ML, Grandpre J, Katz DL, Shenson D. The impact of key modifiable risk factors on leading chronic conditions. Prev Med. 2019;120:113-8.

2. Khandelwal S, Kurpad A, Narayan K. Global non-communicable diseases - the nutrition conundrum. Front Public Health. 2018;6:9.

3. Onufrak SJ, Zaganjor H, Pan L, Lee-Kwan SH, Park S, Harris DM. Foods and beverages obtained at worksites in the United States. J Acad Nutr Diet. 2019:119:999-1008.

4. Orfanos P, Naska A, Trichopoulou A, Grioni S, Boer JM, van Bakel MM, et al. Eating out of home: energy, macro- and micronutrient intakes in 10 European countries. The European Prospective Investigation into Cancer and Nutrition. Eur J Clin Nutr. 2009;63(Suppl 4):S239-62.

5. Todd JE. Changes in consumption of food away from home and intakes of energy and other nutrients among US working-age adults, 2005-2014. Public Health Nutr. 2017:20:3238-46.

6. Lachat C, Nago E, Verstraeten R, Roberfroid D, Van Camp J, Kolsteren P. Eating out of home and its association with dietary intake: a systematic review of the evidence. Obes Rev. 2012;13:329-46.

7. Cavalcante JB, Moreira TMV, Mota CC, Pontes CR, Bezerra IN. Energy and nutrient intake according to away-from-home food consumption in the northeast region: an analysis of the 2008-2009 National Dietary Survey. Rev Bras Epidemiol. 2017;20:115-23.

8. Bes-Rastrollo M, Basterra-Gortari FJ, Sanchez-Villegas A, Marti A, Martínez JA, Martínez-González MA. A prospective study of eating away-from-home meals and weight gain in a Mediterranean population: the SUN (Seguimiento Universidad de Navarra) cohort. Public Health Nutr. 2010;13: 1356-63.

9. Bhutani S, Schoeller DA, Walsh MC, McWilliams C. Frequency of eating out at both fast-food and sit-down restaurants was associated with high body mass index in non-large metropolitan communities in midwest. AJHP. 2018; 32:75-83.

10. Bezerra IN, Curioni C, Sichieri R. Association between eating out of home and body weight. Nutr Rev. 2012;70:65-79.

11. Nago ES, Lachat CK, Dossa RAM, Kolsteren PW. Association of out-of-home eating with anthropometric changes: a systematic review of prospective studies. Crit Rev Food Sci Nutr. 2014;54:1103-16.

12. Robinson E, Jones A, Whitelock V, Mead BR, Haynes A. (Over) eating out at major UK restaurant chains: observational study of energy content of main meals. BMJ. 2018;363:k4982.

13. Roberts SB, Das SK, Suen VMM, Pihlajamäki J, Kuriyan R, Steiner-Asiedu M, et al. Measured energy content of frequently purchased restaurant meals: multi-country cross sectional study. BMJ. 2018;363:k4864. 
14. Block JP, Condon SK, Kleinman K, Mullen J, Linakis S, Rifas-Shiman S, et al. Consumers' estimation of calorie content at fast food restaurants: cross sectional observational study. BMJ. 2013;346:f2907.

15. Burton S, Tangari AH, Howlett E, Turri AM. How the perceived healthfulness of restaurant menu items influences sodium and calorie misperceptions: implications for nutrition disclosures in chain restaurants. J Consum Aff. 2014:48:62-95.

16. Smith LP, Ng SW, Popkin BM. Trends in US home food preparation and consumption: analysis of national nutrition surveys and time use studies from 1965-1966 to 2007-2008. Nutr J. 2013;12:45.

17. Mills S, Adams J, Wrieden W, White M, Brown H. Sociodemographic characteristics and frequency of consuming home-cooked meals and meals from out-of-home sources: cross-sectional analysis of a population-based cohort study. Public Health Nutr. 2018;21:2255-66.

18. Fitzgerald S, Buckley L, Perry IJ, Geaney F. The impact of a complex workplace dietary intervention on Irish employees' off-duty dietary intakes. Health Promot Int. 2019.

19. Mozaffarian D, Angell SY, Lang T, Rivera JA. Role of government policy in nutrition-barriers to and opportunities for healthier eating. BMJ. 2018;361: k2426.

20. Marteau TM, White M, Rutter H, Petticrew M, Mytton OT, McGowan JG, et al. Increasing healthy life expectancy equitably in England by 5 years by 2035: could it be achieved? Lancet. 2019;393:2571-3.

21. Crockett R, King S, Marteau T, Prevost A, Bignardi G, Roberts N, et al. Nutritional labelling for healthier food or non-alcoholic drink purchasing and consumption. Cochrane Database Syst Rev. 2018;2:CD009315.

22. Shangguan S, Afshin A, Shulkin M, Ma W, Marsden D, Smith J, et al. A metaanalysis of food labeling effects on consumer diet behaviors and industry practices. Am J Prev Med. 2019;56:300-14.

23. Food \& Drug Administration (FDA). Menu and vending machines labeling requirements. https://www.fda.gov/food/food-labeling-nutrition/overviewfda-labeling-requirements-restaurants-similar-retail-food-establishments-andvending. Accessed 1 May 2019

24. NSW Food Authority. kJ labelling nutrition information. http://www. foodauthority.nsw.gov.au/ip/legislation/proposals-and-policy/kJ-labellingnutrition-information. Accessed 1 May 2019

25. Ontario Ministry of Health and Long-Term Care. New menu labelling regulation. http://health.gov.on.ca/en/news/bulletin/2016/hb_20160927. aspx. Accessed 1 May 2019.

26. Department of Health. Public health responsibility deal. https:// responsibilitydeal.dh.gov.uk/. Accessed 8 Oct 2018.

27. Food Safety Authority of Ireland (FSAI). Putting calories on menus in Ireland - technical guidance for food businesses. Dublin: FSAl; 2012.

28. Health Service Executive (HSE). Guidance for calorie posting implementation. Dublin: HSE; 2015

29. Vanderlee L, Hammond D. Does nutrition information on menus impact food choice? Comparisons across two hospital cafeterias. Public Health Nutr. 2014;17:1393-402.

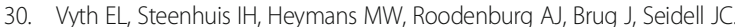
Influence of placement of a nutrition logo on cafeteria menu items on lunchtime food choices at Dutch work sites. J Am Diet Assoc. 2011;111:131-6.

31. Block JP. The calorie-labeling saga_federal preemption and delayed implementation of public health law. N Engl J Med. 2018;379:103.

32. Huang Y, Pomeranz JL, Cash SB. Effective national menu labeling requires accuracy and enforcement. J Acad Nutr Diet. 2018;118:989-93.

33. Fitzgerald S, Gilgan L, McCarthy M, Perry IJ, Geaney F. An evaluation and exploration of Irish food-service businesses' uptake of and attitudes towards a voluntary government-led menu energy (calorie) labelling initiative. Public Health Nutr. 2018;21:3178-91.

34. Robinson E, Burton S, Gough T, Jones A, Haynes A. Point of choice kilocalorie labelling in the UK eating out of home sector: a descriptive study of major chains. BMC Public Health. 2019;19:649.

35. Urban LE, Dallal GE, Robinson LM, Ausman LM, Saltzman E, Roberts SB. The accuracy of stated energy contents of reduced-energy, commercially prepared foods. J Am Diet Assoc. 2010;110:116-23.

36. Urban LE, McCrory MA, Dallal GE, Das SK, Saltzman E, Weber JL, et al. Accuracy of stated energy contents of restaurant foods. JAMA. 2011;306: 287-93.

37. Feldman C, Murray D, Chavarria S, Zhao H. Menu label accuracy at a university's foodservices. An exploratory recipe nutrition analysis. Appetite. 2015:92:24-8.
38. World Cancer Research Fund International. Building momentum: lessons on implementing a robust front-of-pack food label. London: World Cancer Research Fund International; 2019.

39. Damschroder LJ, Aron DC, Keith RE, Kirsh SR, Alexander JA, Lowery JC. Fostering implementation of health services research findings into practice: a consolidated framework for advancing implementation science. Implement Sci. 2009;4:50

40. Powell BJ, Fernandez ME, Williams NJ, Aarons GA, Beidas RS, Lewis CC, et al. Enhancing the impact of implementation strategies in healthcare: a research agenda. Front Public Health. 2019;7:3.

41. Carroll C, Booth A, Leaviss J, Rick J. "Best fit" framework synthesis: refining the method. BMC Med Res Methodol. 2013;13:37.

42. Coxon K, Chisholm A, Malouf R, Rowe R, Hollowell J. What influences birth place preferences, choices and decision-making amongst healthy women with straightforward pregnancies in the UK? A qualitative evidence synthesis using a 'best fit' framework approach. BMC Pregnancy Childbirth. 2017;17:103.

43. Shaw RL, Holland C, Pattison HM, Cooke R. Patients' perceptions and experiences of cardiovascular disease and diabetes prevention programmes: a systematic review and framework synthesis using the theoretical domains framework. Soc Sci Med. 2016;156:192-203.

44. Veinot TC, Senteio CR, Hanauer D, Lowery JC. Comprehensive process model of clinical information interaction in primary care: results of a "bestfit" framework synthesis. J Am Med Inform Assoc. 2017;25:746-58.

45. Stokes T, Shaw EJ, Camosso-Stefinovic J, Imamura M, Kanguru L, Hussein J. Barriers and enablers to guideline implementation strategies to improve obstetric care practice in low-and middle-income countries: a systematic review of qualitative evidence. Implement Sci. 2016;11:144

46. Kerins C, McSharry J, Hayes C, Perry IJ, Geaney F, Kelly C. Barriers and facilitators to implementation of menu labelling interventions to support healthy food choices: a mixed methods systematic review protocol. Syst Rev. 2018;7:88.

47. Moher D, Liberati A, Tetzlaff J, Altman DG. Preferred reporting items for systematic reviews and meta-analyses: the PRISMA statement. Ann Intern Med. 2009;151:264-9.

48. Nilsen P, Bernhardsson S. Context matters in implementation science: a scoping review of determinant frameworks that describe contextual determinants for implementation outcomes. BMC Health Serv Res. 2019;19: 189.

49. Damschroder LJ. Clarity out of chaos: use of theory in implementation research. Psychiatry Res. 2019; In Press.

50. Kirk MA, Kelley C, Yankey N, Birken SA, Abadie B, Damschroder L. A systematic review of the use of the consolidated framework for implementation research. Implement Sci. 2015;11:72.

51. Pluye P, Gagnon M-P, Griffiths F, Johnson-Lafleur J. A scoring system for appraising mixed methods research, and concomitantly appraising qualitative, quantitative and mixed methods primary studies in mixed studies reviews. Int J Nurs Stud. 2009;46:529-46.

52. Carroll C, Booth A, Lloyd-Jones M. Should we exclude inadequately reported studies from qualitative systematic reviews? An evaluation of sensitivity analyses in two case study reviews. Qual Health Res. 2012;22: 1425-34.

53. Hill CE, Knox S, Thompson BJ, Williams EN, Hess SA, Ladany N. Consensual qualitative research: an update. J Couns Psychol. 2005;52:196.

54. Hill CE, Thompson BJ, Williams EN. A guide to conducting consensual qualitative research. Couns Psychol. 1997;25:517-72.

55. Thomas J, Harden A. Methods for the thematic synthesis of qualitative research in systematic reviews. BMC Med Res Methodol. 2008;8:45

56. Vyth EL, Van Der Meer EW, Seidell JC, Steenhuis $\mathrm{H}$. A nutrition labeling intervention in worksite cafeterias: an implementation evaluation across two large catering companies in the Netherlands. Health Promot Int. 2011;27: 230-7.

57. Roodenburg AC, Payens IJ, Vrijhof C. Menu labeling in "out-of-home" sector: opportunities, barriers, and needs with respect to use of health communication in restaurants. Ann Nutr Metab. 2013;63(suppl1):1054.

58. Jeong JY, Kim E, Yang IS, Ham S. Motivators and barriers to provision of nutritional information in restaurants. Korean J Hosp Tourism. 2015;24:227-43.

59. Clegg S, Jordan E, Slade Z. An evaluation of provision of calorie information by catering outlets. United Kingdom: Food Standards Agency; 2009.

60. Toronto Public Health. Voluntary menu labelling pilot project: final report. Ontario: Toronto Public Health; 2015. 
61. Geaney F, Kelly C, Scotto Di Marrazzo J, Gilgan L, McCarthy M, Perry IJ. Evaluation of the uptake of voluntary calorie posting on menus in Ireland. Dublin: Department of Health; 2015.

62. Ottawa Public Health. Report on Ottawa restaurant survey. Ottawa: Ottawa Public Health; 2013.

63. Ray K, Clegg S, Davidson R, Vegeris S. Evaluation of Caloriewise: a Northern Ireland pilot of the display of calorie information in food catering businesses. Northern Ireland: Food Standards Agency; 2013.

64. Mah CL, Vanderlinden L, Mamatis D, Ansara DL, Levy J, Swimmer L. Ready for policy? Stakeholder attitudes toward menu labelling in Toronto, Canada. Can J Public Health. 2013;104:e229-34.

65. Food Safety Authority of Ireland (FSAI). Calories on menus in Ireland. A report on a national consultation. Dublin: FSAl; 2012.

66. Maestro V, Salay E. Restaurant nutrition and health information in the municipality of Campinas, São Paulo, Brazil: expectations of managers with respect to benefits and obstacles. J Food. 2008;19:262-9.

67. Britt JW, Frandsen K, Leng K, Evans D, Pulos E. Feasibility of voluntary menu labeling among locally owned restaurants. Health Promot Pract. 2011;12:1824.

68. Din N, Zahari MSM, Othman CN, Abas R. Restaurant operator's receptiveness towards providing nutritional information on menu. Procedia Soc Behav Sci. 2012;50:699-709.

69. Almanza BA, Nelson D, Chai S. Obstacles to nutrition labeling in restaurants. J Am Diet Assoc. 1997;97:157-61.

70. Zick A, Wake Y, Reeves S. Nutrition labelling in restaurants: a UK-based case study. NUFS. 2010;40:557-65.

71. Shupe E. Obstacles to participation in menu labeling observed by the independent foodservice establishments [degree of doctor of philosophy]. Minnesota: Walden University; 2013.

72. Logue D, Kennelly J, Keaveney E, O'Connor D, Bhriain SN, Flynn M. Calorie menu labelling in Ireland: a survey of food service businesses. Proc Nutr Soc. 2013;72:E167.

73. Greenhalgh T, Robert G, Macfarlane F, Bate P, Kyriakidou O. Diffusion of innovations in service organizations: systematic review and recommendations. Milbank Q. 2004;82:581-629.

74. Lukas CV, Holmes SK, Cohen AB, Restuccia J, Cramer IE, Shwartz M, et al. Transformational change in health care systems: an organizational model. Health Care Manag Rev. 2007:32:309-20.

75. Fixsen DL, Naoom SF, Blase KA, Friedman RM. Implementation research: a synthesis of the literature. Tampa: University of South Florida, Louis de la Parte Florida Mental Health Institute, The National Implementation Research Network (FMHI Publication\# 231); 2005.

76. Glisson C, Schoenwald SK. The ARC organizational and community intervention strategy for implementing evidence-based children's mental health treatments. Ment Health Serv Res. 2005;7:243-59.

77. Birken SA, Bunger AC, Powell BJ, Turner K, Clary AS, Klaman SL, et al. Organizational theory for dissemination and implementation research. Implement Sci. 2017;12:62.

78. Cabana MD, Rand CS, Powe NR, Wu AW, Wilson MH, Abboud P-AC, et al, Why don't physicians follow clinical practice guidelines?: a framework for improvement. JAMA. 1999;282:1458-65.

79. Hamilton AB, Mittman BS, Eccles AM, Hutchinson CS, Wyatt GE. Conceptualizing and measuring external context in implementation science: studying the impacts of regulatory, fiscal, technological and social change. Implement Sci. 2015;10(Suppl 1):A72.

80. Shediac-Rizkallah MC, Bone LR. Planning for the sustainability of community-based health programs: conceptual frameworks and future directions for research, practice and policy. Health Educ Res. 1998;13:87-108.

81. Willging CE, Aarons GA, Trott EM, Green AE, Finn N, Ehrhart MG, et al. Contracting and procurement for evidence-based interventions in publicsector human services: a case study. Admin Pol Ment Health. 2016;43:675-92.

82. Stirman SW, Kimberly J, Cook N, Calloway A, Castro F, Charns M. The sustainability of new programs and innovations: a review of the empirical literature and recommendations for future research. Implement Sci. 2012;7:17.

83. Nilsen P, Ståhl C, Roback K, Cairney P. Never the twain shall meet? - a comparison of implementation science and policy implementation research. Implement Sci. 2013;8:63.

84. Hannan MT, Freeman J. The population ecology of organizations. Am J Sociol. 1977:82:929-64.

85. Birken SA, Mayer DK, Weiner BJ. Survivorship care plans: prevalence and barriers to use. J Cancer Educ. 2013;28:290-6.
86. Krall E, Close J, Parker J, Sudak M, Lampert S, Colonnelli K. Innovation pilot study: acute Care for Elderly (ACE) unit-promoting patient-centric care. HERD. 2012;5:90-8.

87. Tsai Y. Health care industry, customer orientation and organizational innovation: a survey of Chinese hospital professionals. Chin Manag Stud. 2013;7:215-29.

88. Consolidated framework for implementation research. https://cfirguide.org/. Accessed 17 Apr 2019.

89. Proctor EK, Powell BJ, McMillen JC. Implementation strategies: recommendations for specifying and reporting. Implement Sci. 2013:8:139.

90. Powell BJ, Waltz TJ, Chinman MJ, Damschroder LJ, Smith JL, Matthieu MM et al. A refined compilation of implementation strategies: results from the expert recommendations for implementing change (ERIC) project. Implement Sci. 2015;10:21.

91. Waltz TJ, Powell BJ, Fernández ME, Abadie B, Damschroder LJ. Choosing implementation strategies to address contextual barriers: diversity in recommendations and future directions. Implement Sci. 2019:14:42.

92. Fernandez ME, ten Hoor GA, van Lieshout S, Rodriguez SA, Beidas RS, Parcel $\mathrm{G}$, et al. Implementation mapping: using intervention mapping to develop implementation strategies. Front Public Health. 2019;7:158.

93. Bartholomew Eldredge LK, Markham CM, Ruiter RA, Fernández ME, Kok G, Parcel GS. Planning health promotion programs: an intervention mapping approach. 4th ed. San Francisco: Jossey-Bass; 2016.

94. Powell BJ, Beidas RS, Lewis CC, Aarons GA, McMillen JC, Proctor EK, et al. Methods to improve the selection and tailoring of implementation strategies. J Behav Health Serv Res. 2017:44:177-94.

95. Morley B, Martin J, Niven P, Wakefield M. Public opinion on food-related obesity prevention policy initiatives. Health Promot J Austr. 2012;23:86-91.

96. Farrell LC, Moore VM, Warin MJ, Street JM. Why do the public support or oppose obesity prevention regulations? Results from a south Australian population survey. Health Promot J Austr. 2019;30:47-59.

97. Thow AM, Jones A, Schneider CH, Labonté R. Global governance of front-of pack nutrition labelling: a qualitative analysis. Nutrients. 2019;11:268.

98. Wang Z, Norris SL, Bero L. Implementation plans included in World Health Organisation guidelines. Implement Sci. 2016;11:76.

99. Wang Z, Norris SL, Bero L. The advantages and limitations of guideline adaptation frameworks. Implement Sci. 2018;13:72.

100. Escoffery C, Lebow-Skelley E, Haardoerfer R, Boing E, Udelson H, Wood R, et al. A systematic review of adaptations of evidence-based public health interventions globally. Implement Sci. 2018;13:125.

101. Campbell M, Katikireddi SV, Hoffmann T, Armstrong R, Waters E, Craig P. TIDieR-PHP: a reporting guideline for population health and policy interventions. BMJ. 2018;361:k1079.

102. Powell WW, DiMaggio PJ. The new institutionalism in organizational analysis. Chicago: University of Chicago Press; 2012.

103. Swinburn BA, Kraak VI, Allender S, Atkins VJ, Baker PI, Bogard JR, et al. The global syndemic of obesity, undernutrition, and climate change: the lancet commission report. Lancet. 2019:393:791-846.

104. Raine KD, Ferdinands AR, Atkey K, Hobin E, Jeffery B, Nykiforuk Cl, et al. Policy recommendations for front-of-package, shelf, and menu labelling in Canada: moving towards consensus. Can J Public Health. 2017;108:409-13.

105. Aarons GA, Hurlburt M, Horwitz SM. Advancing a conceptual model of evidence-based practice implementation in public service sectors. Admin Pol Ment Health. 2011;38:4-23.

106. Nilsen P. Making sense of implementation theories, models and frameworks. Implement Sci. 2015;10:53.

\section{Publisher's Note}

Springer Nature remains neutral with regard to jurisdictional claims in published maps and institutional affiliations. 